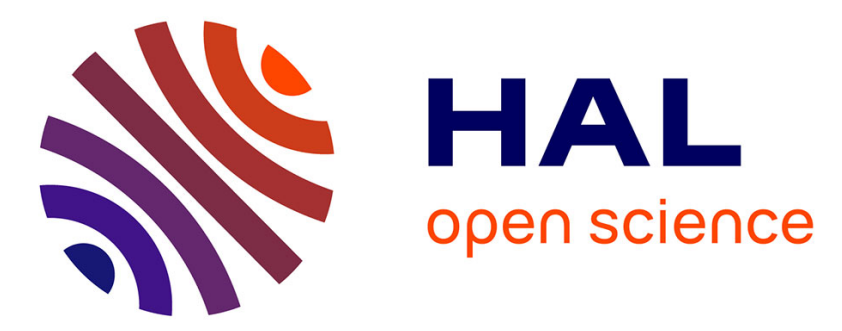

\title{
Effect of compensation on recombination into Si doped $(\mathrm{Ga}, \mathrm{Al}) \mathrm{As}$
}

\author{
J. Mazzaschi, J. Barrau, J.C. Brabant, M. Brousseau, H. Maaref, F. Voillot, \\ M. C. Boissy
}

\section{- To cite this version:}

J. Mazzaschi, J. Barrau, J.C. Brabant, M. Brousseau, H. Maaref, et al.. Effect of compensation on recombination into Si doped (Ga, Al)As. Revue de Physique Appliquée, 1980, 15 (4), pp.861-864. 10.1051/rphysap:01980001504086100 . jpa-00244796

\section{HAL Id: jpa-00244796 https://hal.science/jpa-00244796}

Submitted on 1 Jan 1980

HAL is a multi-disciplinary open access archive for the deposit and dissemination of scientific research documents, whether they are published or not. The documents may come from teaching and research institutions in France or abroad, or from public or private research centers.
L'archive ouverte pluridisciplinaire HAL, est destinée au dépôt et à la diffusion de documents scientifiques de niveau recherche, publiés ou non, émanant des établissements d'enseignement et de recherche français ou étrangers, des laboratoires publics ou privés. 


\title{
Effect of compensation on recombination into Si doped $(\mathrm{Ga}, \mathrm{Al}) \mathrm{As}\left({ }^{*}\right)$
}

\author{
Laboratoire de Physique des Solides (**), \\ I.N.S.A., avenue de Rangueil, 31077 Toulouse Cedex, France \\ M. C. Boissy \\ R.T.C., La Radiotechnique-Compelec, B.P. 6025, 14001 Caen Cedex, France
}

J. Mazzaschi, J. Barrau, J. C. Brabant, M. Brousseau, H. Maaref and F. Voillot

\begin{abstract}
Résumé. - Au moyen d'une expérience de cathodoluminescence pulsée, nous avons étudié les recombinaisons radiatives dans des couches épitaxiées $(\mathrm{Ga}, \mathrm{Al})$ As fortement dopé ; le dopant est $\mathrm{Si}$ ou Ge. Dans des couches homogènes dopées au silicium nous avons obtenu les conditions de fort rendement lumineux et de longue durée de vie observées dans les diodes électroluminescentes réalisées par double épitaxie en phase liquide de $(\mathrm{Ga}, \mathrm{Al}) \mathrm{As}$ sur substrat GaAs. Les phénomènes sont bien expliqués en considérant l'effet des fluctuations des impuretés chargées dans les semiconducteurs fortement compensés sur les queues de densité d'états en bords de bande interdite.
\end{abstract}

\begin{abstract}
Using a time-resolved cathodoluminescence technique, we have investigated the radiative recombination in highly doped ( $\mathrm{Ga}, \mathrm{Al}$ )As epitaxial layers (the dopant was $\mathrm{Si}$ or $\mathrm{Ge}$ ). We have realized in homogeneous Si-doped epitaxial $(\mathrm{Ga}, \mathrm{Al})$ As layers the conditions of large luminescence efficiency and great decay time usually observed in L.E.D. obtained by double liquid phase epitaxy of (Ga, Al)As on $\mathrm{GaAs}$ substrate. The phenomena are well explained if we consider the effect of charge impurity fluctuations in compensated semiconductors on the density of state tails at the edges of the band-gap.
\end{abstract}

1. Introduction. - III-V semiconductors compounds and their alloys have a great importance in electroluminescent devices technology. Among them $(\mathrm{Ga}, \mathrm{Al}) \mathrm{As}$ is particularly used due to the possibility to fabricate heterostructures.

The production of some optoelectronic components requires highly doped materials and some active zones of the structure may be strongly compensated. Theoretical models have been proposed $[1,2,3]$ which actually provide rather good tools for understanding the main electrical and optical properties of such semiconductors.

Some properties of $(\mathrm{Ga}, \mathrm{Al}) \mathrm{As}$ electroluminescent devices obtained by double liquid phase epitaxy of ( $\mathrm{Ga}, \mathrm{Al}) \mathrm{As}$ on $\mathrm{N}$ type $\mathrm{GaAs}$ substrate - specially the long decay time - led us to investigate the properties of bulk materials and to suspect the possibility of an important compensation effect by the Si dopant incorporated during the epitaxial growth, specially at the edge of the junction.

(*) Conférence présentée au Congrès de la Société Française de Physique (Toulouse).

(**) Associé au C.N.R.S.
We worked at room temperature and at $77 \mathrm{~K}$. The cathodoluminescence experiment has been described previously [4]. The light is focused into a $0.6 \mathrm{~m}$ Jobin-Yvon grating monochromator with slits set at $3 \mathrm{meV}$ resolution. The detection is achieved by a R.C.A. C 31034 photomultiplier and boxcar technique : the time resolution is $3 \mathrm{~ns}$ for the whole system. The electron beam is pulsed at $800 \mathrm{~Hz}$ and the square pulse characteristics are the rise time $(\$ 1 \mathrm{~ns})$ the duration $(10-1000 \mathrm{~ns})$ the voltage $(20-100 \mathrm{kV})$ and the current density $\left(0.01-2 \mathrm{~A} \mathrm{~cm}^{-2}\right)$. In the present study we work at $50 \mathrm{kV}$ - so that the electron beam penetrates at $11 \mu \mathrm{m}$ into $\mathrm{GaAs}$ - and $1.5 \mathrm{~A} \mathrm{~cm}^{-2}$. In each situation we choose a pulse duration greater than the luminescence decay time. Under such conditions, the stationary carrier density attained is $\approx 2 \times 10^{18} \mathrm{~cm}^{-3}$ when the carrier lifetime is $\approx 20 \mathrm{~ns}$ which is a typical value.

We used $15 \mu \mathrm{m}$ epitaxial layers grown under electric current applied during the liquid phase epitaxy on GaAs substrates. Such conditions favour the homogeneity of the $\mathrm{Al}$ composition into the layer. The electron beam was accelerated under $30 \mathrm{kV}$ in order to reduce the penetration at $6 \mu \mathrm{m}$, which considerably reduces the substrate luminescence. 
2. Ge doped samples. - The cathodoluminescence spectra recorded at $77 \mathrm{~K}$ is shown on (Fig. 1). The high injection level eliminate any effect of the conduction band tail on the spectra. In each spectrum the high energy band must be associated to the band to band recombination and the low energy band to the conduction band-acceptor states recombination. At high doping level the interactions between acceptors produce an acceptor band which broadens the spectrum line. The different positions of the spectra come from the different values of $x$ into the ternary alloy $\left(\mathrm{Ga}_{1-x} \mathrm{Al}_{x}\right)$ As for one sample to another.

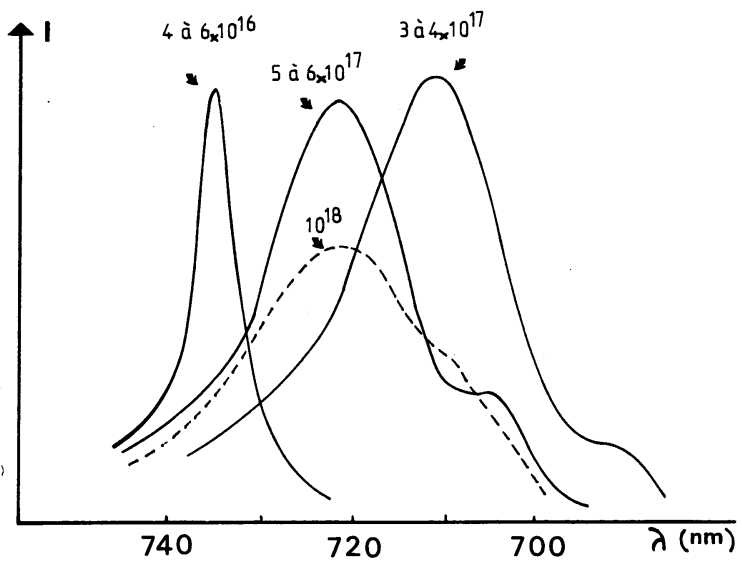

Fig. 1. - Stationary spectra of Ge-doped ( $\mathrm{Ga}, \mathrm{Al}) \mathrm{As}$ epitaxial layers at $77 \mathrm{~K}$.

The band to band recombination dominates the relatively sharp spectra of lightly-doped sample. The band to band recombination and the conduction band to acceptor states recombination are competitive processes at intermediate doping levels which produces two separated lines - or one line and one shoulder $30 \mathrm{meV}$ apart. The conduction band-acceptor states recombination dominates at high $\mathrm{Ge}$-densities. Also the lifetime (table I) is not wavelength dependant.

3. Si doped samples. - 3.1 EXPERIMENT. - A set of epitaxial layers having a fixed aluminium concentration $(x=0.3)$ and various silicon densities has been produced. The crystal growth conditions have been adjusted in order to obtain large compensation effects due to the amphoteric properties of silicon (table II). The main features of the cathodoluminescence spectra at $77 \mathrm{~K}$ are the following :

(i) The bandwidth of the luminescence line increases and the position shifts towards long wavelengths as the compensation ratio increases (Fig. 2).

(ii) The luminescence line shifts towards short wavelength as the injection level increases and this effect enhances as the compensation ratio increases (Fig. 3).

(iii) The decay time of the integrated luminescence increases very quickly with the compensation ratio from 6 ns (sample 159) until $300 \mathrm{~ns}$ (sample 155).
Tables I, II. - (Ga, Al)As epitaxial layers, $\mathrm{Ge}$ or $\mathrm{Si}$ doped. $N_{\mathrm{D}}-N_{\mathrm{A}}$ densities are measured by the Copeland technique. The decay-time of the luminescence has been measured at three different wavelengths in each spectrum. The compensation ratio increases as the silicon concentration in the four samples (see table II).

Table I

\begin{tabular}{|c|c|c|c|}
\hline Ge dopping & $\begin{array}{c}\tau(\mathrm{ns}) \\
\text { low energy } \\
\text { side }\end{array}$ & $\begin{array}{c}\tau(\mathrm{ns}) \\
\text { peak } \\
\text { position }\end{array}$ & $\begin{array}{c}\quad \tau \text { (ns) } \\
\because \text { high } \\
\text { energy side }\end{array}$ \\
\hline - & - & - & - \\
\hline 4 à $6 \times 10^{16}$ & 28 & 14 & 12 \\
\hline 3 à $4 \times 10^{17}$ & 9 & 9 & 9 \\
\hline 5 à $6 \times 10^{17}$ & 10 & 9 & 10 \\
\hline $10^{18}$ & 8 & 8 & 9 \\
\hline
\end{tabular}

Table II

$\begin{array}{cccc}\begin{array}{c}\text { Si } \\ \text { doping } \\ N^{0}\end{array} & \begin{array}{c}\text { Si concentration in } \\ \text { liquid phase }\end{array} & \begin{array}{c}\text { Type } \\ -\end{array} & \begin{array}{c}\text { donors } \\ \text { density } \\ \text { cm }^{-3}\end{array} \\ 159 & 0 & \begin{array}{c}- \\ \text { n }\end{array} & 4 \text { à } 6 \times 10^{15} \\ 166 & 10^{-3} & \text { n } & 4 \text { à } 5 \times 10^{16} \\ 163 & 2 \times 10^{-3} & \text { n } & 10^{17} \\ 152 & 5 \times 10^{-3} & \text { n } & 5 \times 10^{16} \\ 155 & 10 \times 10^{-3} & \text { n } & 7 \times 10^{16} \\ 160 & 20 \times 10^{-3} & ? & 2 \times 10^{16} \\ 150 & 50 \times 10^{-3} & \text { p } & 2 \times 10^{17}\end{array}$

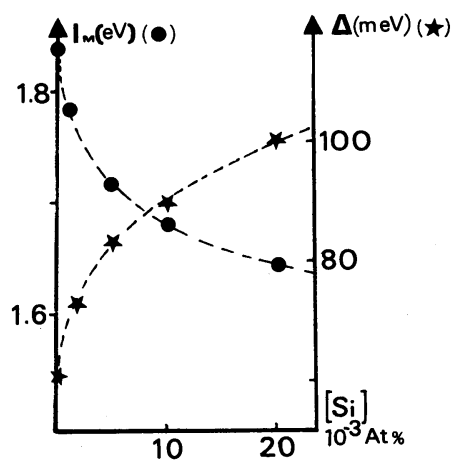

Fig. 2. - Si-doped $(\mathrm{Ga}, \mathrm{Al})$ As epitaxial layers. The position of the maximum of the luminescence versus the concentration of silicon introduced into the sample at $77 \mathrm{~K}$. The linewidth of the luminescence band versus the concentration of silicon into the sample at $300 \mathrm{~K}$.

Also, this decay time varies continuously from great values on the long wavelength side to small values on the short wavelength side of each spectrum (Fig. 4). This effect produces a shift of the luminescence line towards long wavelengths during the decay (Fig. 5). Further, the luminescence decay at each wavelength is not exponential, which proves that the corresponding recombination is not a single first order process. 


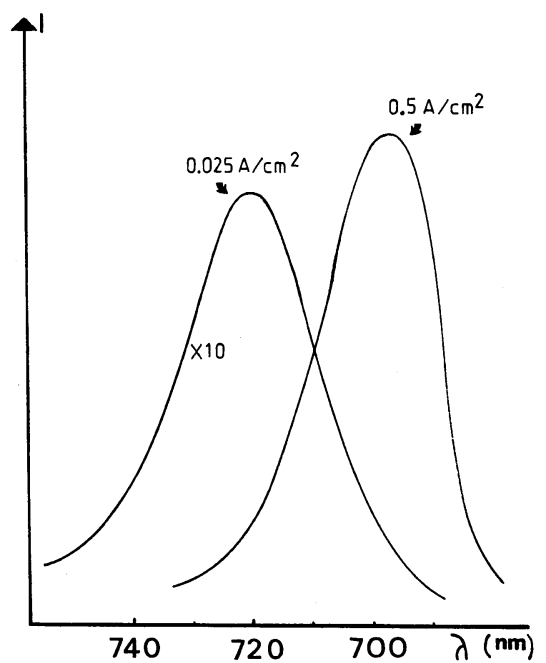

Fig. 3. - Si-doped $(\mathrm{Ga}, \mathrm{Al}) \mathrm{As}$ epitaxial layers at $77 \mathrm{~K}$. The luminescence band shifts towards short wavelengths as the injection level I increases.

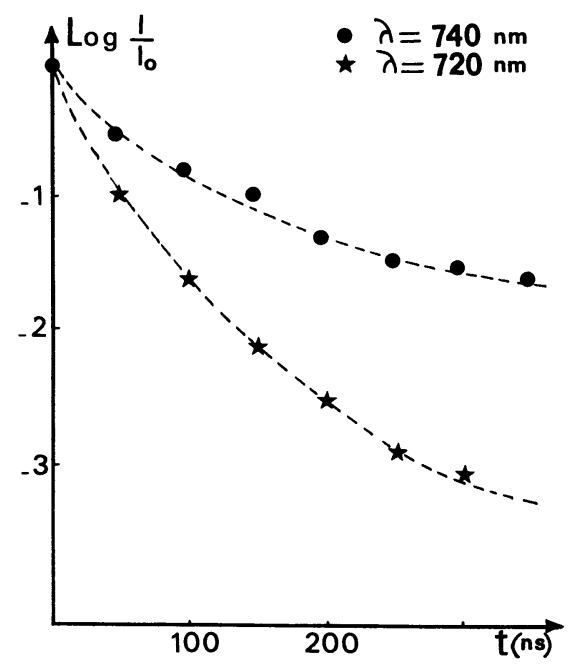

Fig. 4. - Si-doped (Ga, Al)As epitaxial layers at $77 \mathrm{~K}$. The luminescence decay for the sample $\mathrm{Si} 166$ at two different wavelengths.

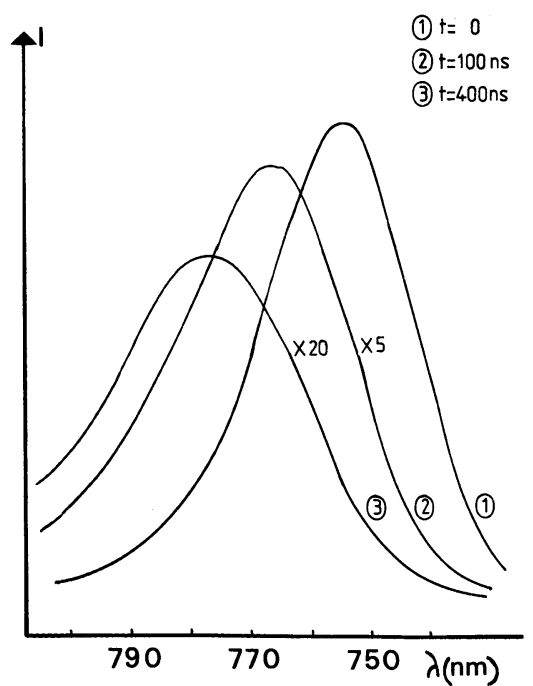

Fig. 5. - Si doped $(\mathrm{Ga}, \mathrm{Al}) \mathrm{As}$ epitaxial layers at $77 \mathrm{~K}$ (sample $\mathrm{Si}-160$ ). Time resolved spectra recorded at three different times during the decay (the origine $t=0$ is choosen at the end of the excitation).
3.2 INTERPRETATION. - First of all, each of the features (i)-(iii) is specific of ( $\mathrm{Ga}, \mathrm{Al}) \mathrm{As}$ compensated samples. Neither of them could be observed in noncompensated materials. Such results are well understood if we consider the theoretical studies on density of state tails at the edges of the forbidden bandgap due to fluctuations of charged impurity densities.

The special case of high compensation has been discussed by Shklovskii and Efros [1-3]. When the concentration of charged impurities $\mathrm{N}$ is moderately high, the depth of a potential well formed by their fluctuation (the size of which is $R$ ) is given by [2]

$$
\Delta E \approx \frac{e\left(N R^{3}\right)^{1 / 2}}{\chi R}
$$

where $e$ is the electronic charge and $\chi$ is the permittivity. Clearly, the dimensions of the effective fluctuations and consequently the depth of the potential wells are limited by the screening radius $R_{\mathrm{s}}$. When $N_{\mathrm{A}}$ increases to value comparable with $N_{\mathrm{D}}$, the depth $\Delta E$ increases because of the increase in the total concentration of the charged impurities and because of the increase of $R_{s}$.

These potential wells are able to localize not only free holes but also free electrons in spite of their small effective mass. It is shown in [2] that $R_{\mathrm{s}}$ increases much more rapidly when the screening is due to such localized carriers than when it is produced by free carriers :

$$
R_{\mathrm{s}} \approx \frac{N_{\mathrm{D}}^{1 / 3}}{n^{2 / 3}}
$$

Considering the typical example $N=3.5 \times 10^{18}$, $n=2 \times 10^{17}$, we obtain

$$
R_{\mathrm{s}} \approx 45 \mathrm{~nm} \text { and } \Delta E \approx 100 \mathrm{meV} .
$$

So, groups of electrons and groups of holes separate in the material the first occupying regions having a net excess of positive fixed charges and the second regions having a net excess of negative fixed charges. The radiative transitions between free electron and free holes proceed by tunnel effect. The energy of the photon emitted is :

$$
h v \approx E_{\mathrm{g}}-2 \Delta E \approx E_{\mathrm{g}}-\frac{2 e\left(N R^{3}\right)^{1 / 2}}{\chi R} .
$$

The value of $R$ governs the degree of overlap of the wave functions of the recombining carriers and consequently the probability i.e. the time constant of the transitions. With such a model, the preceding features (i)-(iii) may be well understood :

(i) An increase of the compensation ratio enhances the potential fluctuations which localize deeper the packets of electrons and holes respectively : this produces the long wavelength shift of the luminescence spectrum and increases the bandwidth.

(ii) An increase of the injection level produces a 
filling of the density of state tails which shifts the spectra towards short wavelengths.

(iii) In each spectrum the long wavelength photons are associated with the recombination of electrons and holes which localize into the deeper potential wells while the short wavelength photons are associated to the recombination of electrons and holes which localize into the shallower wells. But the deeper wells are also the most distant and consequently the transition probability between them is weaker; the reverse is true for the shallower wells. This explains the observed variation of the decay time from one side to the other of each spectral line. A similar interpretation is given for the inter-impurity transition process.

(iv) The mechanism for radiative transitions between separated wells considerably reduces the role of the deep centers in the materials as recombination centers. This explains the large increase of the decay time, now entirely governed by the tunneling probabilities, and the great efficiency of the luminescence of ( $\mathrm{Ga}, \mathrm{Al}) \mathrm{As}, \mathrm{Si}$ doped and compensated materials.

In conclusion, we have realized in homogeneous epitaxial $(\mathrm{Ga}, \mathrm{Al})$ As layers doped with silicon the conditions of large luminescence efficiency and large decay time usually observed into LED obtained by double liquid phase epitaxy of $\mathrm{Si}$ doped ( $\mathrm{Ga}, \mathrm{Al}) \mathrm{As}$ on GaAs N-type substrate. The phenomena are well explained if we consider the effect of charged impurities fluctuations in compensated semiconductors - or compensated zones into the device - on the density of state tails at the edges of the forbidden band gap.

Acknowledgments. - We are indebted R.T.C. La Radiotechnique Compelec (Caen, France) for providing the devices. It is also a pleasure to acknowledge Dr Lebailly, R.T.C. La Radiotechnique Compelec (Caen, France) for helpful discussions.

\section{References}

[1] ShkıovskiI, B. I. and Efros, A. L., Sov. Phys. Semicond. 4 (1970) 249.

[2] ShklovskiI, B. I. and Erros, A. L., Sov. Phys. JETP 33 (1971) $468 ; 34$ (1972) 435.
[3] Levanyuk, A. P. and Opsipov, V. V., Sov. Phys. Semicond. 7 (1973) $721 ; 7$ (1973) 727.

[4] Maaref, H., Barrau, J., Brousseau, M., Collet, J., MazzasCHI, J., Solid State Commun. 229 (1977) 593. 